\title{
MICROCRYSTALLINE SILICON SOLAR CELLS: THEORY AND DIAGNOSTIC TOOLS
}

\author{
Fanny Meillaud, Arvind Shah, Julien Bailat, Evelyne Vallat-Sauvain, Tobias Roschek ${ }^{1,2}$, Bernd Rech ${ }^{1}$, Didier \\ Dominé, Thomas Söderström, Martin Python, Christophe Ballif \\ Institut de Microtechnique de l'Université, $\mathrm{CH}-2000$ Neuchâtel, Switzerland \\ ${ }^{1}$ Institute of Photovoltaics, Forschungszentrum Juelich $\mathrm{GmbH}$, D-52425 Juelich, Germany \\ ${ }^{2}$ Unaxis A.G., Solar Division, Trübbach (SG), Switzerland
}

\begin{abstract}
A simple theoretical model for pin/nip-type $\mu \mathrm{C}-\mathrm{Si}: \mathrm{H}$ solar cells is presented. It is based on a superposition of a drift-dominated collection model and of the classical driftdiffusion transport model of the pn-diode. The model is the basis for a solar cell equivalent circuit, identical to the one introduced by Merten et al. [1], for amorphous cells. The equivalent circuit serves as framework for the diagnosis of faulty solar cells, by selected experimental tools, such as: $\mathrm{J}(\mathrm{V})$ curves, Quantum efficiency (QE) curves, Raman spectroscopy, Fourier-Transform Photo Spectroscopy (FTPS), Variable Intensity Measurements (VIM) [1]. The main parameter that characterizes solar cell "quality" is the fill factor (FF). For best cells FF is over $75 \%$. FF can be reduced by (1) collection problems (characterized by a drop in the collection voltage $\mathrm{V}_{\text {coll }}$ ); (2) shunts (characterized by low shunt resistance $R_{\text {shunt }}$ ); (3) excessive series resistance. Thanks to VIM analysis, it is possible to discriminate experimentally between these 3 types of deficiencies. It is also possible to measure $V_{\text {coll }}$ very easily and link it to fill factor reduction $\Delta F F$. Selected examples of solar cell series and case studies of defective and degraded cells are given.
\end{abstract}

\section{Theoretical Model and Equivalent Circuit}

In extension of earlier work [1] on amorphous silicon (a-Si:H) solar cells, a simple model is proposed here for $\mu \mathrm{c}-\mathrm{Si}: \mathrm{H}$ solar cells: It is based on adding collection current density $\mathrm{J}_{\text {coll }}$, and diode current density $\mathrm{J}_{\text {diode }}$

$$
J_{\text {total }}=J_{\text {coll }}+J_{\text {diode }}
$$

$J_{\text {diode }}$ is given by the drift-diffusion diode model

$$
J_{\text {diode }}=J_{0}\left\{\exp \left(q V_{\text {appl }} / n k T\right)-1\right\}
$$

For $p$-i-n diodes: $\quad J_{\text {coll }}=J_{\text {gen }}-J_{\text {rec }}-J_{\text {shunt }}$

with $\quad J_{\text {rec }} \approx J_{\text {gen }}\left(d_{i} / I_{\text {drift }}\right)$

$J_{\text {gen }}$ is the photogenerated current density, which is, in its turn, proportional to the intensity of incoming light

$J_{\text {rec }}$ is the recombination current density,
$I_{\text {drift }}=\left(\mu \tau_{\text {eff }} \times E_{\text {eff }}\right)$ is the drift length within the i-layer

$\mathrm{J}_{\text {shunt }} \approx \mathrm{V}_{\text {appl }} / \mathrm{R}_{\text {shunt }}$ is the current density through physical micro-shunts (resistance $\mathrm{R}_{\text {shunt }}$ ),

$\mu \tau_{\text {eff }}$ the effective mobility $x$ lifetime product of the i-layer,

$\mathrm{E}_{\text {eff }} \approx\left\{\left(\mathrm{V}_{\mathrm{bi}}-\mathrm{V}_{\mathrm{appl}}\right) / \Psi \mathrm{d}_{\mathrm{i}}\right\}$ the effective electric field within the i-layer $\{\Psi$. is a "form factor" taking into account the deformation of the electric field $\mathrm{E}(\mathrm{x})$ [2], p. 64$\}, \mathrm{V}_{\mathbf{b i}}$ is the built-in voltage, $V_{a p p l}$ the external applied voltage, $d_{i}$ the $i-$ layer thickness, $J_{0}$ the diode reverse saturation current density, $\mathrm{n}$ the diode ideality factor, $\mathrm{q}$ the unit charge, $\mathrm{k}$ the Boltzmann constant and $\mathrm{T}$ the absolute temperature.

$E_{\text {eff }}$ is reduced by space charge: e.g. by ionised contaminants $(\mathrm{O}, \mathrm{B})$ and charged defects.

At $V_{\text {appl }}=0$, eq. (4) becomes: $J_{\text {rec }} \approx J_{\text {gen }}\left(V_{\text {bi }} / V_{\text {coll }}\right)$, where $\mathrm{V}_{\text {coll }}$ is called the "collection voltage" (see below).

This model leads to the equivalent circuit of Fig. 1:

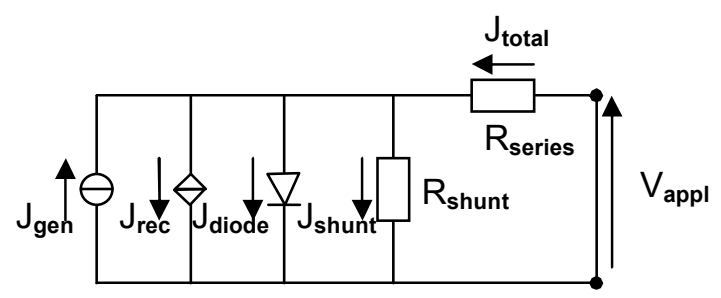

Fig.1 Equivalent circuit for pin-type solar cells [1]; the controlled current sink $J_{\text {rec }}$ \{equation (4)\} depends on i-layer "quality", $\mathrm{R}_{\text {shunt }}$ originates from micro-shunts at the edges or in the bulk of the cell; $R_{\text {series }}$ is given by contacts and TCO; the diode $D$ is represented by eq. (3), and characterized by $J_{0}$ and $n$, where $J_{0}$ is given by material band gap, defect density $N_{\text {defect }}$ and by cell thickness $d_{i}$.

The circuit of Fig. 1 is too complex for electrical system design; it is, however, useful for cell diagnostics, because it splits up the "usual" parallel resistance $R_{p}$ of the "classical" equivalent circuit into 2 parts: recombination losses $\left(\mathrm{J}_{\mathrm{rec}}\right)$ and "true", physical micro-shunts $\left(\mathrm{R}_{\text {shunt }}\right)$. 


\section{Package of Diagnostic Tools}

The following measurement methods have been used to investigate microcrystalline silicon solar cells and to diagnose faults in design and fabrication that may have limiting effects on solar cell performance: - classical J(V) curves at $100 \mathrm{~mW} / \mathrm{cm}^{2}$, - External Quantum Efficiency curves $\{\mathrm{EQE}(\mathrm{hv})\}$, at different values of the bias voltage $V_{\text {bias, }}$

- Raman spectroscopy ( $\rightarrow$ "Raman crystallinity" $X_{c}$ ),

- Fourier-Transform Photocurrent Spectroscopy (FTPS), giving absorption $\alpha(\mathrm{hv})$, preferably on a log $\alpha$ - plot,

- Variable Intensity Measurements (VIM), i.e. J(V) curves at $0.001-100 \mathrm{~mW} / \mathrm{cm}^{2}$.

Raman (used here at $633 \mathrm{~nm}$ ) allows one to evaluate i-layer crystallinity, after fabricating the solar cell [3].

FTPS gives us i-layer defect density $\{$ via $\alpha(0.8 \mathrm{eV})\}$ and structural disorder $\left\{\right.$ via the Urbach energy $E^{0}$, i.e. via the slope of the band-edge in the log a (hv) plot\}; it is also measured on entire pin/n-i-p cells, after fabrication [4].

EQE ( $h v, V_{\text {bias }}$ ) gives information on collection within the ilayer; the latter is also determined by VIM (by evaluating $\left.\mathrm{V}_{\text {coll }}\right)$. VIM [1] gives additional insight into $\mathrm{R}_{\text {shunt }}$ and $\mathrm{R}_{\text {series: }}$ : two critical parameters in thin-film silicon cells.

Table 1 shows the Ideal values obtained today for $\mu \mathrm{c}-$ $\mathrm{Si}: \mathrm{H}$ i-layers and state-of the art (best) $\mu \mathrm{c}-\mathrm{Si}: \mathrm{H}$ solar cells, after carefully tailoring the plasma reactors to the needs of $\mu \mathrm{c}-\mathrm{Si}: \mathrm{H}$ deposition, and after mastering all steps of cell fabrication. It also shows the Range of values that are easily obtained, by transferring deposition systems and other fabrication steps, as they are used for a-Si:H cells, and just increasing $\mathrm{H}_{2}$ dilution, to obtain $\mu \mathrm{c}-\mathrm{Si}: \mathrm{H}$.

\begin{tabular}{|l|l|l|}
\hline Parameter & Ideal & Range \\
\hline Raman crystallinity $\mathrm{X}_{\mathbf{c}}$ & $60 \%$ & $30 \rightarrow 80 \%$ \\
\hline Defect absorption $\alpha(0.8 \mathrm{eV})$ & 0.01 & $0.1 \rightarrow 10 \mathrm{~cm}^{-1}$ \\
\hline Urbach energy E & 35 & \\
\hline EQE $(0 \mathrm{~V}) @ 450 \mathrm{~nm}$ & $70 \%$ & \\
\hline EQE $(0 \mathrm{~V}) @$ Max $(\approx 570 \mathrm{~nm})$ & $85 \%$ & \\
\hline EQE $(0 \mathrm{~V}) @ 700 \mathrm{~nm}$ & $80 \%$ & \\
\hline $\mathrm{EQE}(0 \mathrm{~V}) @ 850 \mathrm{~nm}$ & $50 \%$ & \\
\hline $\mathrm{R}_{\text {shunt }}\left[\mathrm{k} \Omega \mathrm{cm}^{2}\right]$ & 100 & $1 \rightarrow 10$ \\
\hline $\mathrm{R}_{\text {series }\left[\Omega \mathrm{cm}^{2}\right]}$ & 5 & $5 \rightarrow 10$ \\
\hline $\begin{array}{l}\text { Collection voltage } \\
\mathrm{V}_{\text {coll }}=\mu \tau_{\text {eff }} / \Psi \cdot\left(\mathrm{V}_{\mathbf{b i}} / \mathrm{d}_{\mathbf{i}}\right)^{2}\end{array}$ & $80 \mathrm{~V}$ & $20 \rightarrow 75 \mathrm{~V}$ \\
\hline
\end{tabular}

Table 1 Typical parameters for microcrystalline silicon layers/cells, as currently reported in the literature: "Ideal" values refer to best published data; "Range" refers to data published, in general, by many groups (see text).

\section{Analyzing the Fill Factor}

For $\mu \mathrm{c}-\mathrm{Si}: \mathrm{H}$ solar cells, the "ideal" calculated value of FF (given by the $1.1 \mathrm{eV}$ band gap of $\mu \mathrm{c}-\mathrm{Si}: \mathrm{H}$ [5]) is over $75 \%$; however, in practice, cells often exhibit values in the 60 to $70 \%$ range. In thin-film silicon solar cells, there are 3 main reasons why $F F$ is reduced to values below its limit value: $(A)$ recombination losses within the ilayer and at the $p / i$ and $i / n$ interfaces; $(B)$ partial microshunts through the i-layer (and through the whole cell); $(\mathrm{C})$ contact and doped layers with too high resistivity. In the equivalent circuit of Fig. 1 , effect $(A)$ increases $J_{\text {rec }}$, by decreasing the collection voltage $V_{\text {coll }}=\mu \tau_{\text {eff }} / \Psi \cdot\left(V_{b i} / d_{i}\right)^{2}$; effect $(B)$ decreases $R_{\text {shunt; }}$; effect $(C)$ increases $R_{\text {series }}$.

In case $(A)$ the value of $F F$ is reduced and $J_{\text {rec }}$ increased, as shown schematically in Fig.2, under the assumption that the maximum power point (MPP) remains at the same value of $\mathrm{V}$, when recombination increases

In practice it is important to analyze why the FF of a given cell is low. Here, VIM analysis can help:

Plot log $R_{s c}=f\left\{\log \left(J_{s c}{ }^{-1}\right)\right\}$, as in Fig. 3. (For the definition of $1 / R_{s c}$, see Fig.2.) The slope of the log $R_{s c}$-curve is indeed equal to $V_{\text {coll; }}$ the curve itself goes asymptotically towards $R_{\text {shunt }}$, for $J_{s c} \rightarrow 0$. The asymptote for $J_{s c} \rightarrow$ infinity would give $R_{\text {series }}$ but is difficult to locate, unless very high light intensities (>>1 sun) are used.

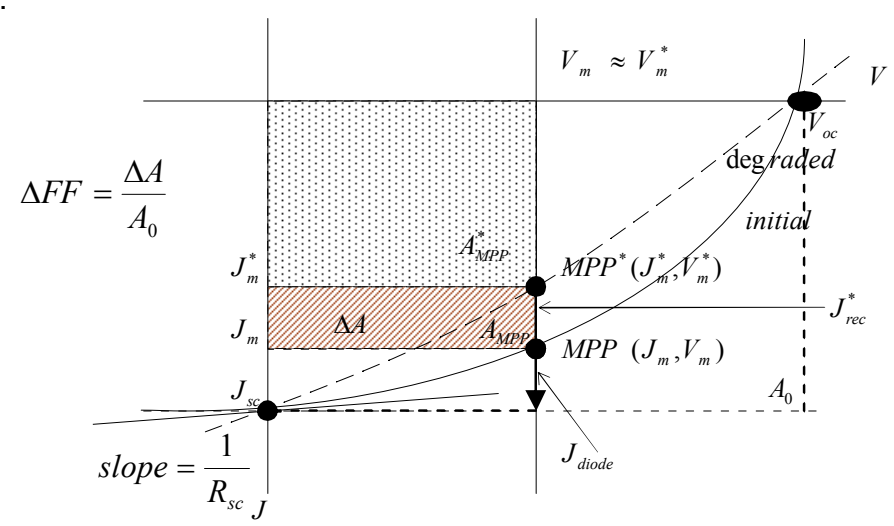

Fig. 2 Schematic representation of $\mathrm{J}(\mathrm{V})$ curves for ideal cell and cell with strong recombination losses $\mathrm{J}$ 'rec.

The following relationship (from [5]) links the collection voltage $V_{\text {coll }}=V_{b i} l_{\text {drift }} / d_{i}$ ) to the fill factor reduction:

$$
\Delta F F \approx \frac{V_{b i}}{V_{\text {coll }}} \cdot 90 \%
$$

As $\mathrm{V}_{\mathrm{bi}}$ is around $1 \mathrm{~V}$, a collection voltage $\mathrm{V}_{\text {coll }}$ of only $10 \mathrm{~V}$, as is often encountered with "medium-quality" $\mu \mathrm{c}-\mathrm{Si}: \mathrm{H}$ i-layers, will lead to a FF reduction of $9 \%(\rightarrow 66 \%)$ !

Note: The determination of $\mathrm{V}_{\text {coll }}$ (by VIM) is probably the easiest way to determine the "quality" of the i-layer. 


\section{Investigation of selected solar cells}

(a) Variable gas flow series

Above diagnostic tools were applied to a series of $\mu \mathrm{c}$ Si:H solar cells deposited by Roschek et al. [6] under "high pressure depletion (HPD)" conditions. HPD allows one to increase the deposition rate, whilst maintaining i-layer quality. However, HPD generally requires high gas flows, especially high $\mathrm{H}_{2}$ flows: economically, this can be a serious disadvantage. In the series investigated here, Roschek et al. [6] therefore fabricated $\mu \mathrm{c}-\mathrm{Si}: \mathrm{H}$ solar cells under HPD conditions, at $13.56 \mathrm{MHz}$, but with step-wise reduced $\mathrm{H}_{2}$ flow rates; the $\left[\mathrm{H}_{2}\right]:\left[\mathrm{SiH}_{4}\right]$ dilution ratio was adjusted in such a way, as to keep Raman crystallinity $\mathrm{X}_{\mathrm{c}}$ constant, at about $60 \%$. One notices (Table 2) that FF drops from $72 \%$ to $66 \%$ when the $\mathrm{H}_{2}$ flow rate is reduced from $750 \mathrm{sccm}$ to $50 \mathrm{sccm}$. The main reason for this drop can be revealed by (a) VIM and (b) FTPS measurements (see Fig. 3 and Table 2): It is an increase in i-layer defect density. However, $\mathrm{V}_{\text {coll }}$ suffers a stronger reduction than $\{\alpha(0.8 \mathrm{eV})\}^{-1}$. This may be explained by stronger Oincorporation at lower gas flow rates, leading to field deformation (increase in $\Psi$ ) and lower $E_{\text {eff. }}$

\begin{tabular}{|l|l|l|}
\hline $\mathrm{H}_{2}$ flow $[\mathrm{sccm}]$ & 750 & 50 \\
\hline i-layer thickness $[\mu \mathrm{m}]$ & 1.29 & 1.09 \\
\hline $\mathrm{X}_{\mathrm{c}}[\%]$ & 66.5 & 60.0 \\
\hline $\mathrm{J}_{\text {sc }}\left[\mathrm{mA} / \mathrm{cm}^{2}\right]$ & 21.9 & 21.8 \\
\hline $\mathrm{EQE}(@ 700 \mathrm{~nm}, 0 \mathrm{~V})$ & 0.70 & 0.72 \\
\hline $\mathrm{EQE}(@ 700 \mathrm{~nm},-1.5 \mathrm{~V})$ & 0.70 & 0.74 \\
\hline$R_{\text {shunt }}\left[\mathrm{k} \Omega \mathrm{cm}^{2}\right]$ & 140 & 25 \\
\hline $\mathrm{V}_{\text {oc }}[\mathrm{mV}]$ & 538 & 497 \\
\hline $\mathrm{FF}[\%]$ & 72.4 & 66.2 \\
\hline $\mathrm{V}_{\text {coll }}=\mu \tau_{\text {eff }} / \Psi \cdot\left(\mathrm{V}_{\mathrm{bi}} / \mathrm{d}_{\mathrm{i}}\right)^{2}[\mathrm{~V}]$ & 59.4 & 12.5 \\
\hline$\mu \tau_{\text {eff }}\left[\mathrm{cm}{ }^{2} / \mathrm{V}\right]$ & $8.0 \cdot 10^{-7}$ & $1.1 \cdot 10^{-7}$ \\
\hline$\alpha(0.8 \mathrm{eV})\left[\mathrm{cm}^{-1}\right]$ & $2.5 \cdot 10^{-3}$ & $4.4 \cdot 10^{-3}$ \\
\hline $\mathrm{E}_{0}[\mathrm{meV}]$ & 35.8 & 39.6 \\
\hline
\end{tabular}

Table 2 Solar cell parameters for 2 cells of the variable gas flow series: a "good" cell at $750 \mathrm{sccm} \mathrm{H}_{2}$ flow and a "poor" cell at $50 \mathrm{sccm}$. Table 2 does not aim at showing the limits of the HPD deposition method. Its only aim is to show how solar cell parameters are affected when i-layer quality is reduced. (Note: There are indeed many publications in the last PV conferences, which address the issue of fabricating excellent $\mu \mathrm{c}-\mathrm{Si}: \mathrm{H}$ solar modules at higher deposition rates and with reasonable gas usage.)

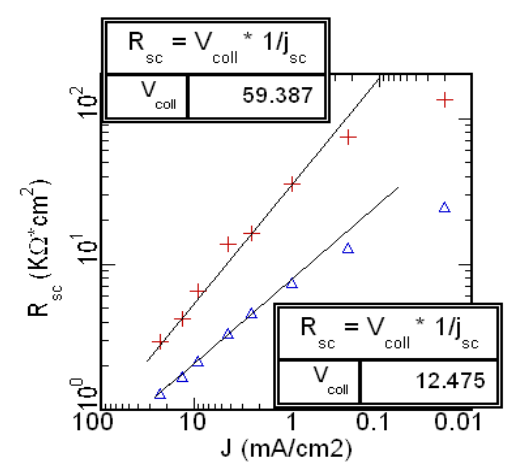

Fig. 3 VIM analysis for 2 cells of the variable gas flow series; the curves for log $R_{s c}=f\left\{\log \left(J_{s c}{ }^{-1}\right)\right\}$ have, for intermediate values of $J_{s c}$, slopes that are equal to $V_{\text {coll; }}$ the curves tend asymptotically towards $R_{\text {shunt, }}$, for $\mathrm{J}_{\mathrm{sc}} \rightarrow 0$.

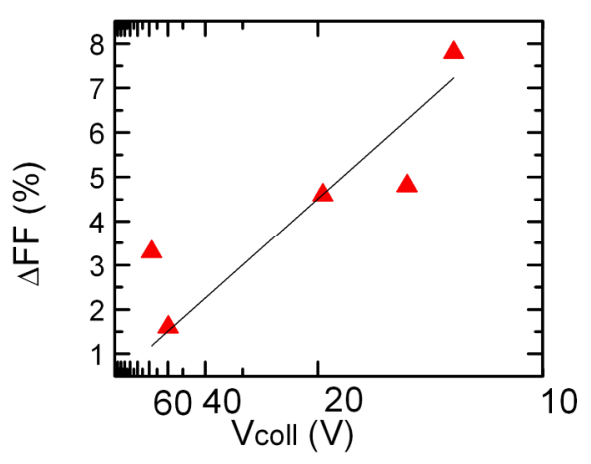

Fig. $4 \Delta \mathrm{FF}$ as a function of $\mathrm{V}_{\text {coll }}$; points marked as $\Delta$ are measured values for the variable gas flow series; straight line is a theoretical prediction according to eq. (5); here $\Delta \mathrm{FF}=\mathrm{FF}_{0}-\mathrm{FF}$, where $\mathrm{FF}_{0}=75 \%$

\section{(b) Light-induced degradation}

Microcrystalline solar cells have a mild form of lightinduced degradation or "Staebler-Wronski Effect (SWE)". The degradation effect is (relatively) lower for cells with a high value of Raman crystallinity. Cells with intermediate crystallinity $\left(X_{c} \approx 50 \%\right)$ show (in absolute terms) the best performance, both in the initial and in the degraded state $[5,7]$ : This is linked to a minimum in $\alpha(0.8 \mathrm{eV})$ and in $\mathrm{J}_{\text {rec }}$, and to a maximum in both $\mu \tau_{\text {eff }}$ and $V_{\text {coll. }}$ Light-induced degradation manifests itself, in general, by an increase in $\alpha(0.8 \mathrm{eV})$ and by corresponding variations in $\mathrm{V}_{\text {coll, }} \mu \tau_{\text {eff }}$ and $J_{\text {rec. }}$. Most other solar cell parameters are hardly affected [7]. Table 3 and Fig. 5 illustrate this. 


\begin{tabular}{|l|c|c|}
\hline & Before & After \\
\hline Raman crystallinity $\mathrm{X}_{\mathrm{c}}$ & \multicolumn{2}{|c|}{$50 \%$} \\
\hline $\mathrm{J}_{\text {sc }}\left(\mathrm{mA} / \mathrm{cm}^{2}\right)$ & 18.3 & 18.0 \\
\hline $\mathrm{EQE}(@ 700 \mathrm{~nm}, 0 \mathrm{~V})$ & 0.50 & 0.49 \\
\hline $\mathrm{EQE}(@ 700 \mathrm{~nm},-1.5 \mathrm{~V})$ & 0.55 & 0.54 \\
\hline$V_{\text {oc }}[\mathrm{mV}]$ & 527 & 525 \\
\hline FF $[\%]$ & 66.2 & 63.9 \\
\hline$R_{\text {shunt }}\left[\mathrm{k} \Omega \mathrm{cm}^{2}\right]$ & 170 & 140 \\
\hline$V_{\text {coll }}=\mu \tau_{\text {eff }} / \Psi \cdot\left(\mathrm{V}_{\mathrm{bi}} / \mathrm{d}_{\mathrm{i}}\right)^{2}[\mathrm{~V}]$ & 14.2 & 10.1 \\
\hline$\mu \tau_{\text {eff }}\left[\mathrm{cm}^{2} / \mathrm{V}\right]$ & $4.3 \cdot 10^{-7}$ & $3.0 \cdot 10^{-7}$ \\
\hline$\alpha(0.8 \mathrm{eV})\left[\mathrm{cm}^{-1}\right]$ & $2.6 \cdot 10^{-3}$ & $4.6 \cdot 10^{-3}$ \\
\hline $\mathrm{E}_{0}[\mathrm{meV}]$ & 36.2 & 36.4 \\
\hline
\end{tabular}

Table 3 Solar cell parameters for a typical pin cell (2 $\mu \mathrm{m}$ thick, $X_{c} \approx 50 \%$ ), before/after light-soaking. Note the drop in $\mathrm{V}_{\text {coll }}$ from 14.2 to $10.1 \mathrm{~V}$, corresponding to an increase in $\Delta \mathrm{FF}$ from 6.3 to $8.9 \%$, according to eq. (5).

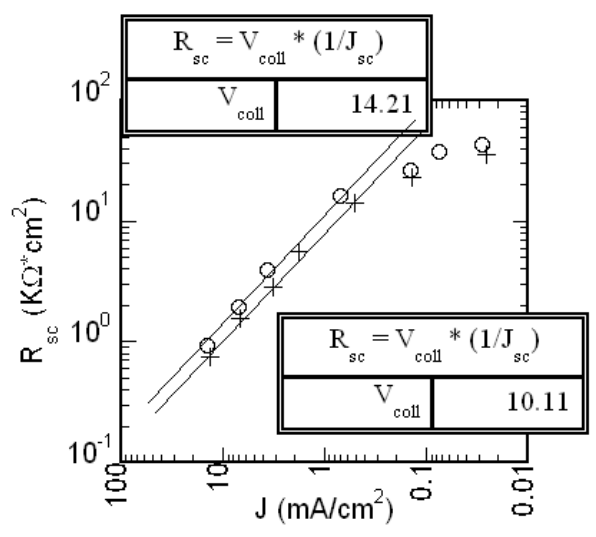

Fig. $5 \mathrm{VIM}$ analysis for the cell of Table 3 (dilution series, $X_{c} \approx 50 \%$ ), before $\mathbf{O}$ and after + light-soaking (see Fig. 3 for explanations about VIM analysis)

\section{(c) Micro-shunts}

Microcrystalline solar cells are often afflicted by microshunts (which can be seen by VIM, as illustrated in Fig.6); such micro-shunts lead often to a reduction in FF, according to the following equation [5]:

$$
\Delta \mathrm{FF}=\mathrm{R}_{\text {equ }} / \mathrm{R}_{\text {shunt }}
$$

with

$\mathrm{R}_{\text {equ }} \approx 2 \mathrm{k} \Omega \mathrm{cm}^{2}$;

$\mathrm{R}_{\text {shunt }}$ in $\left[\mathrm{k} \Omega \mathrm{cm}^{2}\right], \Delta \mathrm{FF}$ in \%

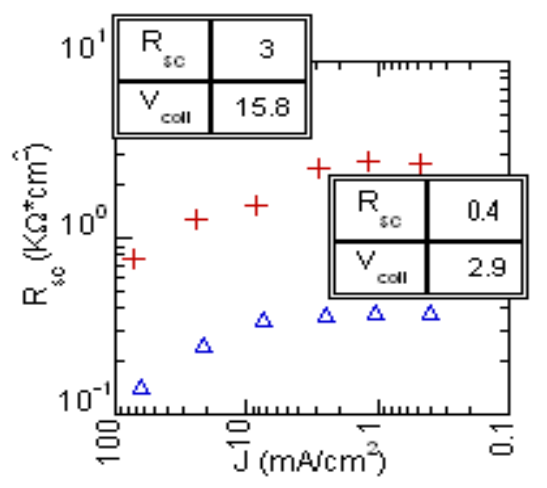

Fig. 6 VIM analysis for 2 typical $\mu \mathrm{C}-\mathrm{Si}$ :H cells with microshunts (a) lightly shunted + , i.e. $R_{\text {shunt }}=3 \mathrm{k} \Omega \mathrm{cm}^{2}$; the FF at AM 1.5 is almost not affected; (b) heavily shunted $\triangle$, $R_{\text {shunt }}=0.4 \mathrm{k} \Omega \mathrm{cm}^{2}$; at $A M 1.5 \Delta \mathrm{FF}=4.5 \%$, by comparison with a non-shunted cell of the same run.

\section{CONCLUSIONS}

For microcrystalline silicon solar cells adequate diagnostic tools, such as Raman and FTPS are important. A standard indicator for cell performance is the fill factor $(\mathrm{FF})$. Because of the frequent occurrence of cracks and shunts in microcrystalline layers, it is particularly important to analyze whether a low value of FF is due to low shunt resistance $R_{\text {shunt }}$ or to increased recombination, i.e. to a low value of the "collection voltage" $V_{\text {coll. }}$. This can be done by VIM. $V_{\text {coll }}$ turns out to be a key parameter to evaluate the "quality" of the i-layer within entire cells. With spectrally-resolved VIM it should, in future, also be possible to separate the effects of bulk and interfaces.

\section{ACKNOWLEDGEMENTS}

Support was given by FNSRS, grant FN200021-107469.

\section{REFERENCES}

[1] J. Merten et al., IEEE Transactions on Electron Devices, ED-45, 1998, pp. 423-429

[2] C. Hof, Ph.D. thesis, Univ. of Neuchâtel, 2000.

[3] J. Bailat et al., J. Appl. Phys., 93, 2003, pp. 5727-5732,

[4] A. Poruba et al., J. Non-Crystalline Solids, 299-302, 2002, pp. 536-540.

[5] F. Meillaud, Ph.D. thesis, Univ. of Neuchâtel, 2006.

[6] T. Roschek et al., Thin Solid Films, 451-452, 2004, pp. 466-499

[7] F. Meillaud et al., Proc. of the $20^{\text {th }}$ EU PVSEC, ISBN 3936338-19-1, 2005, pp. 1509-1512. 